\title{
Actividad antioxidante de la melatonina sobre el hígado graso inducido por etionina en ratones ${ }^{\#}$
}

\author{
Antioxidant activity of melatonin on fatty liver induced by ethionine in mice \\ SM Ferraro, A López-Ortega* \\ Unidad de Investigación Ciencias Funcionales “Dr. Haity Moussatché”, Decanato de Ciencias Veterinarias, Universidad \\ Centroccidental "Lisandro Alvarado", Barquisimeto, Venezuela
}

\begin{abstract}
SUMMARY
The aim of this study was to determine the antioxidant activity of melatonin in female mice with ethionine-induced hepatic oxidative stress (HOS), and the effect of this hormone on the gluthatione peroxidase enzyme antioxidant activity. Twenty adult female NMRI mice were given intraperitoneally $3 \mathrm{mg} / \mathrm{kg}$ melatonin in $1 \%$ ethanol daily for 15 days, and $1 \%$ ethanol to the control group. On the $13^{\text {th }}$ day of treatment, fatty liver was induced to both groups using $7.5 \mathrm{mg} / 0.02 \mathrm{~kg}$ ethionine. After 48 hours of food restriction, mice were sacrificed and livers dissected and sampled. Fixed tissue was used for hystopathologic analyses, and the supernatant obtained from an homogenated was used to determine concentrations of malondialdehyde (MDA), conjugate dienes (DC), triglycerides (TG) and gluthatione peroxidase enzyme (GPx). Data were processed through SPSS v10.0 for Windows using the " $\mathrm{t}$ " test $(\mathrm{P} \leq 0.05)$, and the results were expressed as $\mathrm{X} \pm \mathrm{SD}$ in $\mathrm{mg} \mathrm{TG}, \mathrm{nm}$ MDA and $\mathrm{nm} \mathrm{DC} / \mathrm{mg}$ proteins and per $\mathrm{g}$ of humid tissue and $\mathrm{mU} / \mathrm{mg}$ proteins for GPx. Concentrations of TG, MDA and DC were lower $(\mathrm{P}<0.001)$, while GPx activity was higher $(\mathrm{P}<0.05)$ in the treated group. It is concluded that administration of MLT at the given dose reduced the induced HOS in female mice. Also, administration of the hormone reduced the fatty liver and increased GPx activity.
\end{abstract}

Palabras clave: hígado graso, estrés oxidativo, melatonina, ratón.

Key words: fatty liver, oxidative stress, melatonin, mice.

\section{INTRODUCCION}

El oxígeno comprende aproximadamente el $21 \%$ de la atmósfera de la Tierra y es esencial para la vida de los organismos aeróbicos. Sin embargo, en ciertos estados las formas reactivas del oxígeno o radicales libres provenientes del $\mathrm{O}_{2}$ pueden ser letales para los tejidos de aquellos organismos que dependen de él para vivir (Beyer y col 1998). La mayor parte del oxígeno inspirado es usado para generar energía en forma de ATP; sin embargo, $5 \%$ es convertida a radicales libres (RL), eventualmente tóxicos (Reiter 1996).

Los RL son moléculas reactivas capaces de existir en forma independiente y poseen un electrón desapareado en sus orbitales (Haliwell y Gutteridge 1989). Las especies oxígeno reactivas pueden atacar los lípidos, proteínas, ácidos nucleicos y azúcares para producir un daño irreversible de las células (Suzuki y col 1997). Cuando el daño oxidativo causado a las células es sobre las moléculas de lípidos se denomina peroxidación lipídica y el proceso ocasionado por los RL es llamado estrés oxidativo, fenómeno considerado como la causa del deterioro de ciertos tejidos en diversos

Aceptado: 07.03.2007.

\# Financiamiento a través del Consejo de Desarrollo Científico y Humanístico (CDCHT).

* Apartado Postal 267, Barquisimeto, Venezuela; aurau@ @otmail. com desórdenes fisiopatológicos como hipoxia, inflamación e isquemia reperfusión de los tejidos (Reiter y col 1994).

El hígado graso (HG) o hepatoesteatosis puede ser de etiología metabólica, nutricional (Alpers y Isselbacher 1975), farmacológica como el hígado graso causado por la administración de antibióticos (Hautekecte 1995), toxicológica, entre otras. También se puede mencionar el hígado graso por etanol, por tetracloruro de carbono, etionina, entre otros. El hígado graso es una patología en la cual han sido involucrados los radicales libres, y en el HG inducido por etionina (ET) se observa un notable aumento de los radicales libres, indicativo de estrés oxidativo hepático (Aarsaether y col 1988, López-Ortega y col 1997).

Sin embargo, el organismo ha desarrollado un sistema de defensa antioxidante para limitar la formación de los RL. Así, cabe mencionar enzimas como catalasa (CAT), glutatión peroxidasa (GPx), superóxido dismutasa (SOD) y glutatión transferasa (GSH transferasa), que regulan la formación de ellos o pueden neutralizarlos una vez formados. También hay compuestos antioxidantes ingeridos por la dieta, tales como las vitaminas $\mathrm{C}$ y $\mathrm{E}$ y el $\mathrm{B}$-caroteno, capaces de capturar a los RL (Reiter 1996). Además, se ha determinado que tanto la melatonina endógena como exógena pueden ayudar a neutralizarlos antes que ejerzan su actividad (Tan y col 1994).

Por su parte, la melatonina (MLT) es la principal hormona secretada por la glándula pineal y es conocida como un modulador biológico para diversas funciones tales como el sueño, fisiología retinal, actividad reproductiva 
estacional, ritmos circadianos, función inmunológica y antioxidante por su capacidad recolectora de radicales libres (Beyer y col 1998). Así, es usada para el tratamiento del insomnio, prevención de algunos tipos de cáncer y también se emplea para proteger las células de los efectos dañinos producidos por los RL durante el envejecimiento (Antunes y col 1999).

La melatonina regula la expresión génica de enzimas antioxidantes como la superóxido dismutasa (SOD) y glutatión peroxidasa (GPx) y en concentraciones séricas fisiológicas incrementa el ARNm de SOD y GPx en células neuronales (Mayo y col 2002). Tres mecanimos de acción hormonal son discutidos para esta amina biogénica: una vía de señalización de membrana, una vía señaladora nuclear que puede estar mediada por el factor de transcripción RZR/ROR y una vía recolectora de radicales libres independiente de receptores (Wiesenberg 1998). La finalidad de este estudio fue determinar el efecto protector de la melatonina en el estrés oxidativo hepático inducido por etionina en ratones hembras.

\section{MATERIAL Y METODOS}

\section{POBLACION Y MUESTRA}

La población estuvo representada por ratones de la cepa NMRI (Nacional Medicine Research Institute) procedentes del Bioterio Central de la Universidad Centroccidental "Lisandro Alvarado". La alimentación fue en base a alimento comercial (Protinal, Valencia, Venezuela) para ratas y ratones de laboratorio, agua ad libitum. De esa población se seleccionaron al azar 40 ratones (Mus musculus) hembras adultas jóvenes con promedio de 30 $\mathrm{g}$ de peso vivo.

\section{PROCEDIMIENTO}

Los animales se dividieron en dos grupos, a saber: grupo control (Sin MLT) y grupo con MLT (MLT procedente de Sigma, San Louis Mo, USA) constituidos por veinte animales cada uno. De cada grupo, diez animales se destinaron para la cuantificación del estrés oxidativo, y diez para GPx. La MLT fue disuelta en etanol al $1 \%$ y administrada a dosis de $3 \mathrm{mg} / \mathrm{kg}$ vía intraperitoneal (i.p.) durante un período de 15 días, mientras que al grupo control se le administró etanol al $1 \%$ a la misma dosis del grupo experimental.

Dos días antes de completar el tiempo indicado (día 13 de tratamiento), a todos los animales se les indujo hígado graso por inyección i.p. de DL-etionina en dosis de $7,5 \mathrm{mg} / 20 \mathrm{~g}$ peso vivo y se sometieron a un ayuno por 48 horas. En forma simultánea se continuó con la aplicación del antioxidante en el caso del grupo experimental, y con el etanol en el caso del grupo control. Finalizado el ayuno los ratones se sacrificaron bajo ligera eterización y se disecó el hígado. Se tomó una muestra de hígado para análisis histopatológico y otra para obtener un homogeneizado del tejido.

\section{HOMOGENEIZADO DE TEJIDO}

La muestra de hígado utilizada para obtener el homogeneizado se pesó en una balanza analítica Sauter (Alemania) y posteriormente se colocó en buffer Tris- Sacarosa $250 \mathrm{mM}$ $\mathrm{pH} 7,2$ a $4{ }^{\circ} \mathrm{C}$ en una proporción de tres veces su peso, se homogeneizó en un Euroturrax T20b (Alemania). El homogeneizado fue mantenido en hielo y en el sobrenadante se determinó: triglicéridos hepáticos (TG), malondialdehído (MDA), dienos conjugados (DC) y proteínas totales.

\section{CUANTIFICACION DEL GRADO DE HEPATOESTEATOSIS}

Triglicéridos hepáticos: Se determinó la concentración de triglicéridos hepáticos por método enzimático de Trinder (1984), mediante Kit Qualitest (Qualitest C.A., Caracas, Venezuela). Los resultados se expresaron en $\mathrm{mg}$ TG/mg proteínas y por g de tejido húmedo.

Análisis histopatológico: Las muestras de hígado fueron fijadas en solución de formol al 10\%, sometidas a estudio histopatológico. El análisis histopatológico del tejido y las fotomicrografías fueron realizados en el Laboratorio de Patología del Decanato de Ciencias Veterinarias de la Universidad Centroccidental "Lisandro Alvarado". La tinción usada fue hematoxilina-eosina, se determinó la cuantía de hígado graso sobre la base del contenido de vacuolas lipídicas presentes en el tejido.

\section{DETERMINACION DE INDICADORES DE ESTRES OXIDATIVO}

Concentración de MDA por el test para sustancias reaccionantes con el ácido 2- tiobarbitúrico (TBARS): De acuerdo a la técnica de Ohkawa y col (1979). Se midió la absorbancia del producto coloreado en un espectrofotómetro GENESYS 5 (Rochester NY, USA) a una longitud de onda de $532 \mathrm{~nm}$. Los resultados se expresaron en nmoles de MDA/mg proteínas y nmoles MDA/g tejido húmedo.

Concentración de dienos conjugados: Se utilizó el método descrito por Wallin y col (1993). En el sobrenadante se leyó la absorbancia a $232 \mathrm{~nm}$ de longitud de onda, en un Spectronic GENESYS 5. Se utilizó el coeficiente de extinción molar de los DC $27000 \mathrm{M}^{-1} 1$ y los resultados se expresaron en nmoles (DC/mg proteínas) $\times 10^{-5}$ y nmoles (DC/g tej. húmedo) $\times 10^{-5}$.

Determinación de Glutatión peroxidasa: Se procedió a canular la vena porta para lavar el hígado con solución fisiológica mantenida a $4{ }^{\circ} \mathrm{C}$ que contenía EDTA al $10 \%$. Se realizó un homogeneizado del tejido en un Euroturrax durante 10 segundos y se utilizó una solución buffer a $4{ }^{\circ} \mathrm{C}$, compuesta de $50 \mathrm{mM}$ Tris- $\mathrm{HCl}$ y $5 \mathrm{mM}$ EDTA, de pH 7,6 en una relación de $6 \mathrm{ml} / \mathrm{g}$ tejido. La cuantificación de la actividad de la enzima se realizó en el homogenei- 
zado del hígado, mediante kit Calbiochem (La Jolla CA, USA), que tiene como fundamento: un glutatión oxidado produce la reducción de peróxidos orgánicos por acción de la glutatión peroxidasa citosólica, la oxidación del NADPH a NADP se acompaña de una disminución en la absorbancia a $340 \mathrm{~nm}$ por medio de la cual se puede monitorear la actividad enzimática. La absorbancia se determinó en un espectrofotómetro GENESYS 5. El cálculo se realizó de acuerdo a fórmula provista por el kit y los resultados se expresaron en $\mathrm{mU} / \mathrm{mg}$ proteína (actividad específica de la enzima).

\section{DETERMINACION DE PROTEINAS TOTALES}

Se determinaron las proteínas totales en base a la técnica de Bradford (1976) y se utilizó kit Bio Rad (Richmond CA, USA), con un estándar de $1,41 \mathrm{mg} / \mathrm{ml}$ (solución madre) de albúmina sérica bovina (BAS). Las lecturas se realizaron a $540 \mathrm{~nm}$ de longitud de onda, en un espectrofotómetro GENESYS 5.

\section{ANALISIS ESTADISTICO}

Los datos obtenidos en los diversos análisis se sometieron a estudio mediante el paquete estadístico SPSS versión 10.0 para Windows (SPSS Inc, Chicago IL, USA). Se realizó un análisis descriptivo de los datos que presentaron una distribución normal y variancias iguales de acuerdo a la prueba de Levene. Se aplicó prueba "t" $(\mathrm{P} \leq 0,05)$.

\section{RESULTADOS}

Efecto de la melatonina en la funcionalidad hepática. En este estudio se indujo hígado graso en ratones hembras adultas y se les administró melatonina para determinar su efecto en la concentración de triglicéridos hepáticos y por consiguiente en la hepatoesteatosis. La concentración de triglicéridos hepáticos (mg TG/mg proteínas y mg TG/g tejido húmedo) en los animales controles (a los cuales se indujo hígado graso y sin melatonina) fue mayor $(\mathrm{P}<0,001)$ respecto al grupo con MLT (figura 2 paneles a y b).
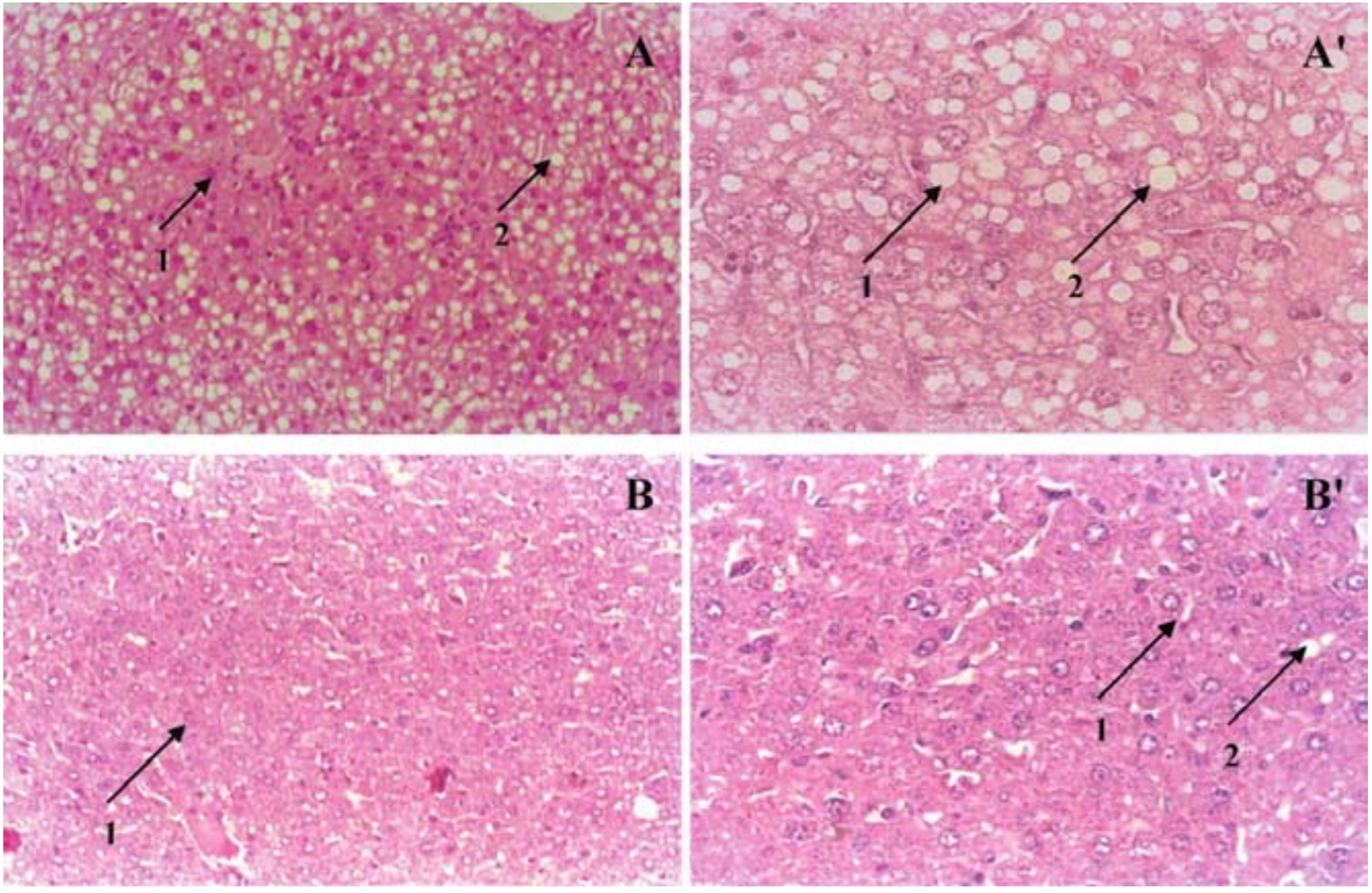

Figura 1. Fotomicrografías de cortes de hígado de ratón con hígado graso inducido sin (A y A') y con melatonina (B y B'). En A (200x H-E) se puede apreciar metamorfosis grasa hepática periportal y se observan (1) vacuolas y (2) tumefacción turbia. En A' (400x H-E) se muestra una metamorfosis grasa hepática severa con vacuolas (1) y marginación del núcleo (2). En B (200x H-E) y B' (400x H-E) se observa una tumefacción turbia difusa (1) y leves cambios grasos.

Photomicrographs of mice fatty liver induced either with (B and B') or without melatonin (A and A'). In A (200x H-E) periportal hepatic fat metamorphosis as well as cloudy tumefaction (2) and fat vacuoles (1) can be appreciated. In A' (400x H-E) a severe hepatic fat metamorphosis with vacuoles (1) and marginalization of the nucleus (2) is observed. In B (200x H-E) and B' (400x H-E) a cloudy tumefaction (1) is observed and slight fatty changes (2). 
a)

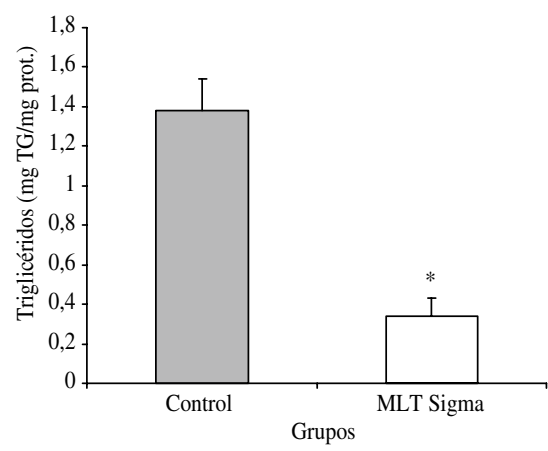

d)

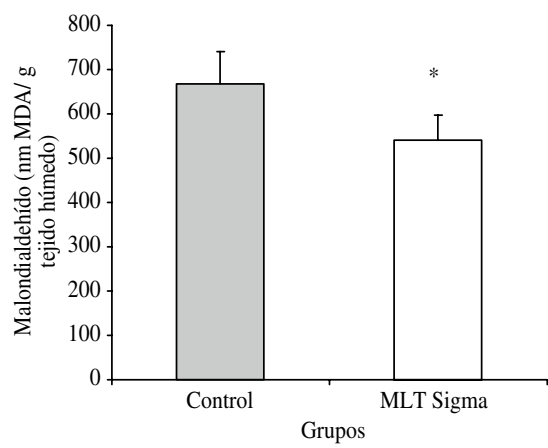

g)

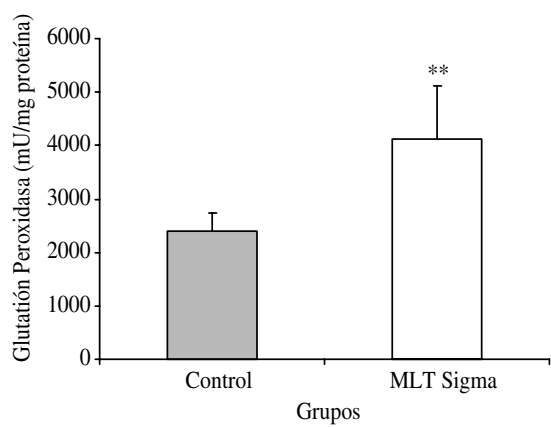

b)

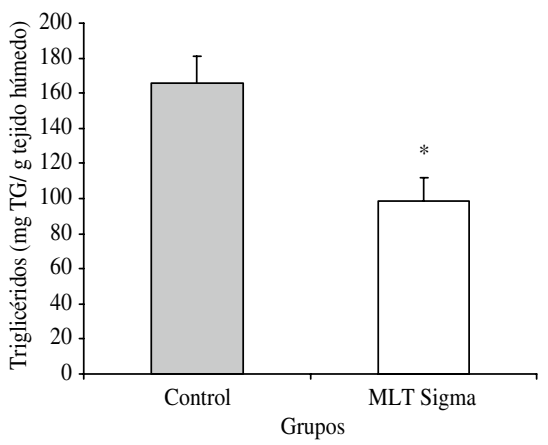

e)

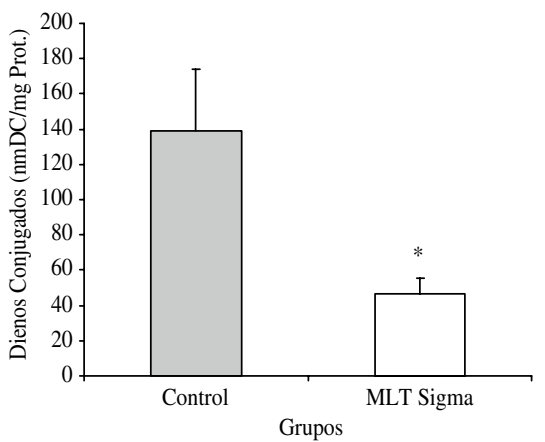

c)

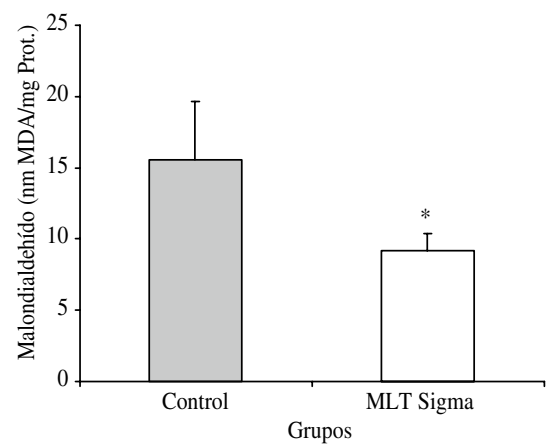

f)

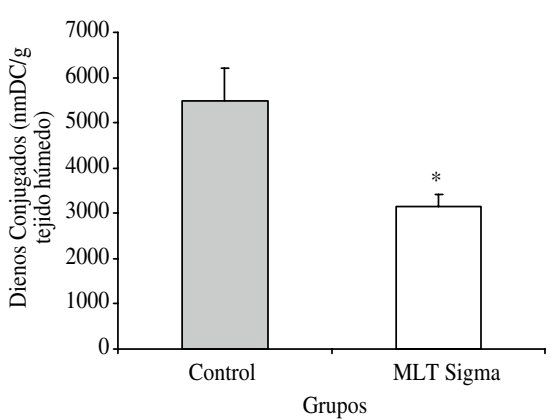

Figura 2. Concentración de: a) y b) triglicéridos, c) y d) malondialdehído, e) y f) dienos conjugados, g) Actividad de glutatión peroxidasa en homogeneizados hepáticos de ratones hembras con hígado graso inducido con (MLT Sigma) y sin melatonina (control). $* \mathrm{P}<0,001 * * \mathrm{P}<0,05$ respecto al grupo control.

Concentration of: triglycerides $(\mathrm{a}, \mathrm{b})$, malondialdehyde $(\mathrm{c}, \mathrm{d})$, conjugate dienes $(\mathrm{e}, \mathrm{f})$, and peroxidase gluthatione enzyme activity $(\mathrm{g})$ in hepatic homogenates with induced fatty liver in female mice under treatment with or without $($ control) melatonin. $* \mathrm{P}<0.001 * * \mathrm{P}<0.05$ respect to control group.

Efecto de la melatonina sobre la concentración de MDA, DC, TG y actividad de la enzima glutatión peroxidasa en homogeneizados hepáticos de ratones con hígado graso inducido. La concentración media de malondialdehído y dienos conjugados expresada en nm MDA/mg proteínas y en $\mathrm{nm} \mathrm{MDA} / \mathrm{g}$ tejido húmedo y en $\mathrm{nmDC} / \mathrm{mg}$ proteínas y por $\mathrm{g}$ tejido húmedo en el grupo control fue mayor $(\mathrm{P}<0,001)$ respecto al grupo con MLT, lo que indicó que el estrés oxidativo hepático fue mayor, en forma significativa en aquellos animales a los cuales no se les administró la hormona (figura 2 paneles c, d, e y f). La actividad de dicha enzima, expresada en $\mathrm{mU} / \mathrm{mg}$ proteínas de GPx fue mayor en forma significativa $(\mathrm{P}<0,05)$ en los homogeneizados hepáticos con etionina y pretratados con MLT, respecto al control (ver panel g, figura 2).

Resultados del análisis histopatológico. En el análisis histopatológico del tejido en los animales con hígado graso inducido y pretratados con melatonina se observaron cambios grasos leves y tumefacción turbia difusa, a diferencia de los animales del grupo control que presentaron metamorfosis grasa hepática severa (figura 1, paneles A, A', B y B'). 


\section{DISCUSION}

La hepatoesteatosis se ha relacionado con un estado de estrés oxidativo, y es así como el hígado graso del alcohólico se asocia con radicales libres provenientes del metabolismo del etanol (Lieber 2001). De igual forma se asocia un estado de estrés oxidativo en hígado graso causado por administración de $\mathrm{CCl}_{4}$, etionina (López-Ortega y col 1997), antibióticos como oxitetraciclina (Ruiz y López-Ortega 2000), entre otros. La etionina es un etil análogo de la metionina y compite con este aminoácido en las vías metabólicas en que él participa. Inhibe la síntesis proteica en la célula hepática (Yokota y col 1982) y afecta la formación de las lipoproteínas del plasma; como consecuencia los lípidos se acumulan en exceso.

En la revisión bibliográfica realizada para este estudio no se encontraron reportes en relación al efecto de la hormona pineal sobre la concentración de triglicéridos hepáticos y la cuantía del hígado graso. El resultado obtenido en esta investigación indicaría que la melatonina ejerce un efecto sobre la hepatoesteatosis, ya que en aquellos animales a los cuales se indujo hígado graso con el hepatotóxico etionina y pretratados con MLT, la concentración de triglicéridos fue menor en relación al grupo control, que no se le administró la hormona. Estos resultados fueron corroborados con el análisis histopatológico del tejido, en el cual se evidenció que en el grupo con MLT, los cambios grasos fueron leves a diferencia del grupo control (figura 1).

Aunque en los animales pretratados con melatonina se evidenciaron daños celulares, que pudieran ser atribuidos al estrés oxidativo implicado en la hepatoesteatosis, el depósito graso (concentración de triglicéridos hepáticos) fue significativamente menor; esto pudiera indicar que la melatonina tiene un efecto directo a nivel hepático que pudiera estar mediado también por la unión de la hormona a un receptor. En este sentido, ha sido descrita la presencia de receptores para la MLT como el MLT1 y el receptor nuclear ROR $\alpha_{1}$ en células hepáticas de ratones (Naji y col 2004); esto pudiera sugerir que la MLT, además de ser scavenger de radicales libres, puede actuar a través de diferentes receptores y cumplir un rol como regulador neuroendocrino de las funciones hepáticas.

En el mismo sentido se midieron indicadores de daño hepático por estrés oxidativo como malondialdehído, dienos conjugados y actividad de la enzima antioxidante glutatión peroxidasa. La concentración media de malondialdehído y dienos conjugados en el grupo control fue mayor respecto al grupo con MLT (figura 2 paneles c, d, e y f).

Estos resultados evidencian la acción protectora de la melatonina sobre el estrés oxidativo hepático inducido por etionina y concuerdan con lo reportado en la literatura. Es así como experimentos realizados por Melchiorri y col (1995) han establecido la propiedad antioxidante de la melatonina contra la peroxidación lipídica hepática. En ratas ellos utilizaron el herbicida paraquat ( $20 \mathrm{o} 70 \mathrm{mg} / \mathrm{kg}$ ), el cual induce daño oxidativo en hígado y pulmón (medido a través de MDA y 4-hidroxialquenos (4 HDA) y demostraron que la melatonina a dosis de $10 \mathrm{mg} / \mathrm{kg}$ administrada previamente al paraquat y luego a intervalos de 6 horas después del mismo, disminuyó los cambios oxidativos causados por el herbicida. Estudios posteriores realizados por estos mismos autores (Melchiorri y col 1996) determinaron que a las 24 horas la dosis letal $50\left(\mathrm{DL}_{50}\right)$ del paraquat se incrementó cuando se administró en ratas, en forma simultánea a la melatonina.

De igual forma, en un estudio realizado en ratas se indujo daño hepático mediante dos inyecciones consecutivas de Tioacetamida ( $300 \mathrm{mg} / \mathrm{kg} /$ i.p.), a intervalos de 24 horas. Las ratas fueron tratadas con melatonina $(3 \mathrm{mg} / \mathrm{kg} /$ día/i.p.) 24 horas previas a la administración del fármaco. Los niveles hepáticos de MDA, proteínas carboniladas y sintasa inducible del óxido nítrico fueron menores, en forma significativa, en aquellos animales a los cuales se les administró el fármaco más la melatonina y la hormona redujo el daño hepático y el estrés oxidativo (Bruck y col 2004). La dosis usada para la presente investigación fue igualmente de $3 \mathrm{mg} / \mathrm{kg} / \mathrm{dí} / \mathrm{i} . \mathrm{p}$. y aunque las condiciones bajo las cuales se generó el estrés oxidativo y el tiempo de pretratamiento con la hormona fueron diferentes, se puede observar que la melatonina tuvo acción protectora sobre el daño oxidativo inducido por el hepatotóxico etionina.

Ha sido determinado que la melatonina protege el ADN nuclear hepático de los efectos de los radicales libres producidos por el cancerígeno safrole. En ratas inyectadas con $300 \mathrm{mg} / \mathrm{kg}$ de safrole seguida de una dosis de melatonina $(0,2$ o $0,4 \mathrm{mg} / \mathrm{kg})$, pudo observarse el efecto protector de la hormona sobre el ADN nuclear de los efectos severos del safrole (Tan y col 1993). Esta protección es una consecuencia de la detoxificación de radicales libres dentro del núcleo, lo que implica que la melatonina pasa al núcleo para proveer protección en el sitio y reducir el daño del ADN (Menéndez-Peláez y Reiter 1993).

Experimentos in vitro también reportan la capacidad recolectora de radicales libres de la melatonina contra los radicales libres. En homogeneizados hepáticos incubados con $0,5 \mathrm{mM}$ de $\mathrm{CCl}_{4}$ la peroxidación lipídica fue elevada; sin embargo, la administración de la hormona previno un aumento de MDA (Daniels y col 1995).

La acción protectora de la melatonina también ha sido estudiada en homogeneizados hepáticos de primates contra el daño lipídico causado por adición exógena de peróxido de hidrógeno e ión ferroso. La melatonina redujo significativamente el MDA y 4 HDA, inclusive aminoró el daño al ADN hepático. Estos hallazgos aportan herramientas para el futuro uso de la hormona para reducir el daño causado por los radicales libres en primates (Cabrer y col 2001).

La literatura reporta una amplia variación en cuanto a las dosis usadas de melatonina en diferentes ensayos, sin embargo, en general indica que existe correspondencia en cuanto al efecto antioxidante de la hormona en diferentes condiciones.

Hay evidencias de experimentos in vitro e in vivo que señalan a la hormona melatonina como antioxidante. Reiter y col (1995) sugieren que la melatonina al ser una molécula con características lipofílicas tiene funciones 
pleiotrópicas, independiente de receptores, no relacionadas con la biología circadiana y que le permiten influenciar tejidos periféricos como blancos directos.

Por su parte los antioxidantes ejercen su actividad en diferente forma, ya que poseen un mecanismo de acción particular sobre ciertas moléculas radicales. La melatonina es considerada un antioxidante, ya que actúa como scavenger de radicales hidroxil ('OH) y peroxilo (ROO') (Beyer y col 1998).

El mecanismo antioxidante de una molécula puede ocurrir por dos vías: el compuesto puede exhibir propiedades antioxidantes directas al recolectar radicales libres (scavenger) y/o al limitar la formación de dichos radicales; la molécula antioxidante también puede actuar al realizar una regulación ascendente de las defensas antioxidantes endógenas. Al respecto, se sugiere que la melatonina puede actuar por las dos vías (Turjanski y col 1998).

En el presente estudio se determinó una enzima antioxidante que ayuda a disponer del peróxido de hidrógeno como lo es la glutatión peroxidasa. La actividad de dicha enzima, expresada en $\mathrm{mU} / \mathrm{mg}$ proteínas, fue mayor en forma significativa $(\mathrm{P}<0,05)$ en los homogeneizados hepáticos con etionina y pretratados con MLT, respecto al control (ver panel g, figura 2). Estos resultados podrían indicar que la MLT promueve un aumento de enzimas antioxidantes en ratones hembras con estrés oxidativo hepático inducido y son similares con lo reportado por Ohta y col (2004) en un estudio en ratas con daño hepático agudo causado por $\mathrm{CCl}_{4}$ a las que se les administró MLT e indican que ésta, administrada posinyección de $\mathrm{CCl}_{4}$ a dosis farmacológicas, previno el daño causado por las especies reactivas del oxígeno y atenuó la disminución en la concentración de ácido ascórbico y SOD, catalasa y glutatión reductasa.

Experimentos realizados por Baydas y col (2002) indican que la melatonina endógena está involucrada en el incremento nocturno de la actividad de la enzima glutatión peroxidasa y los niveles de glutatión oxidado y que además modula el ritmo diario de secreción de la glutatión peroxidasa. Estos mismos autores afirman que la pinealectomía, la cual elimina el ritmo de melatonina, tiene un efecto supresor en los niveles de glutatión peroxidasa.

La acción de la hormona sobre las enzimas antioxidantes ha sido estudiada en más detalle por algunos autores y en este sentido Mayo y col (2002) señalan que la melatonina en concentraciones séricas fisiológicas $(1 \mathrm{nM})$ incrementa el mRNA de la SOD y GPx en dos líneas celulares neuronales y reportan que esta indolamina altera la estabilidad de mRNA para la $\mathrm{Cu}-\mathrm{Zn}$ SOD y GPx.

En el mismo sentido, Winiarska y col (2006) determinaron que la melatonina en dosis de $1 \mathrm{mg} / \mathrm{kg}$ por tres semanas produce un incremento de la actividad de la enzima glutatión peroxidasa a nivel hepático, en conejos con diabetes inducida.

Otro estudio reporta los efectos farmacológicos de la melatonina, vitaminas E y C, glutatión y desferrioxamina, en la peroxidación lipídica hepática inducida por hierro en ratas. Los homogeneizados hepáticos fueron evaluados al estimar los valores de MDA y 4 HDA. Todos los compuestos inhibieron la peroxidación lipídica en forma individual; sin embargo, cuando la melatonina fue combinada con vitamina E, glutatión o vitamina $\mathrm{C}$, los efectos protectores contra la lipoperoxidación inducida por hierro se incrementaron. Los resultados proveen nueva información acerca de la posible combinación de la hormona con antioxidantes clásicos para futuros tratamientos de condiciones relacionadas con los radicales libres (Gitto y col 2001).

Se puede concluir que la administración de la melatonina a dosis de $3 \mathrm{mg} / \mathrm{kg}$ durante 15 días, disminuyó el estrés oxidativo hepático inducido por etinonina en ratones hembras, de acuerdo a la concentración de MDA y DC. En el mismo sentido, la administración de la hormona redujo la hepatoesteatosis y aumentó la actividad específica de la enzima glutatión peroxidasa.

La acción scavenger de la MLT sobre los radicales libres necesita, sin embargo, futuras investigaciones orientadas a determinar la señal de transducción y expresión génica de enzimas antioxidantes por la melatonina y sus metabolitos, además de precisar los niveles de MLT en tejidos y células, modificaciones estructurales de la molécula, entre otros.

La posibilidad de comprender la interrelación entre los antioxidantes y las funciones orgánicas y celulares representaría una opción para la prevención y tratamiento de enfermedades derivadas o relacionadas con radicales libres, en humanos y animales.

\section{RESUMEN}

La finalidad de este estudio fue determinar la actividad antioxidante de la melatonina (MLT) sobre el estrés oxidativo hepático (EOH) inducido por etionina en ratones hembras y su efecto sobre la actividad de la enzima antioxidante glutatión peroxidasa (GPx). A 20 ratones se les administró MLT disuelta en etanol al $1 \%$ en dosis de $3 \mathrm{mg} / \mathrm{kg}$ p.v. vía intraperitoneal, durante 15 días y a los controles etanol 1\%. Al día 13 a ambos grupos se indujo hígado graso por inyección de etionina $7,5 \mathrm{mg} / 0,02 \mathrm{~kg}$. Después de 48 horas de ayuno los animales fueron sacrificados y los hígados disecados. Una muestra se utilizó para análisis histopatólogico y en el sobrenadante obtenido de un homogeneizado se determinó malondialdehído (MDA), dienos conjugados (DC), triglicéridos (TG) y la enzima GPx. Se realizó prueba " $t$ " $(\mathrm{P} \leq 0,05)$. Las concentraciones de TG, MDA y DC fueron menores en el grupo con MLT respecto al control $(\mathrm{P}<0,001)$. La actividad específica $(\mathrm{mU} / \mathrm{mg}$ proteína) $(\mathrm{P}<0,05)$ de GPx fue mayor en el grupo con MLT respecto al control. Se puede concluir que la administración de MLT a dosis de $3 \mathrm{mg} / \mathrm{kg}$ durante 15 días disminuyó el EOH inducido, de acuerdo a la concentración de MDA y DC. En el mismo sentido, la administración de la hormona redujo la hepatoesteatosis y aumentó la actividad de GPx. En este estudio se evidencia la acción protectora de la MLT; sin embargo, el mecanismo de acción a través del cual la hormona ejerce su actividad como antioxidante permanece en discusión.

\section{AGRADECIMIENTOS}

Los autores agradecen al Consejo de Desarrollo Científico Humanístico y Tecnológico (CDCHT) de la Universidad Centroccidental "Lisandro Alvarado" por el financiamiento otorgado para la realización de este estudio. (Proyecto código 010-VE-2001). 


\section{REFERENCIAS}

Aarsaether N, R Berge, A Husoy, A Aarsland, H Kryvi, A Svardal, P Ueland, M Farstad. 1988. Ethionine-induced alterations of enzymes involved in lipid metabolism and their possible relationship to induction of fatty liver. Biochim Biophys Acta 963, 349-358.

Alpers D, K Isselbacher. 1975. Fatty liver: biochemical and clinical aspects. In: Shiff L (ed). Diseases of the liver. Lipincott Company Philadelphia, USA, Pp 815-832.

Antunes F, LR Barclay, K Ingold, M King, J Norris, J Scaiano, F Xi. 1999. On the antioxidant activity of melatonin. Free Radic Biol Med 26, 117-128.

Baydas G, M Gursu, S Yilmaz, S Canpolat, A Yasar, G Cikim, H Canatan. 2002. Daily rhythm of glutathione peroxidase activity, lipid peroxidation and glutathione levels in tissues of pinealectomized rats. Neurosci Lett 323, 195-198.

Beyer CH, J Steketee, D Saphier. 1998. Antioxidant properties of melatoninAn emerging mystery. Biochem Pharmacol 56, 1265-1272.

Bradford MM. 1976. A rapid and sensitive method for the quantitation of microgram of protein utilizing the principle of protein-dye binding. Anal Biochem 72, 248-254.

Bruck R, H Aeed, Y Avni, H Shirin, Z Matas, M Shahmurov, I Avinoach, G Zozulya, N Weizman, A Hochman. 2004. Melatonin inhibits nuclear factor kappa $\mathrm{B}$ activation and oxidative stress and protects against thioacetamide induced liver damage in rats. J Hepatol 40, 86-93.

Cabrer J, S Burkhardt, D Tan, L Manchester, M Karbownik, R Reiter. 2001. Autoxidation and toxicant-induced oxidation of lipid and DNA in monkey liver: reduction of molecular damage by melatonin. Pharmacol Toxicol 89, 225-230.

Daniels W, R Reiter, D Melchiorri, E Sewerinek, M Pablos, G Ortiz. 1995. Melatonin counteracts lipid peroxidation induced by carbon tetrachloride but does not restore glucose-6-phosphatase activity. J Pineal Res 19, 1-6.

Gitto, E, D Tan, R Reiter, M Karbownik, L Manchester, S Cuzzocrea, F Fulia, I Barberi. 2001. Individual and synergistic antioxidative actions of melatonin: studies with vitamin E, vitamin C, glutathione and desferrioxamine (desferoxamine) in rat liver homogenates. J Pharm Pharmacol 53, 1393-1401.

Haliwell B, J Gutteridge. 1989. Lipid Peroxidation: a radical chain reaction. $2^{\text {nd }}$ ed. In: Free Radicals in Biology and Medicine. Clarendon Press, Oxford, UK, Pp 11-14, 188-275.

Hautekeete, ML. 1995. Hepatotoxicity of antibiotics. Acta Gastroenterol Belg 58, 290-296.

Lieber C. 2001. Alcoholic liver injury: pathogenesis and therapy in 2001. Pathol Biol (Paris) 49, 738-752.

López-Ortega A, S Ferraro, C Mendoza, Y Márquez. 1997. Intervención de radicales libres en el hígado graso inducido por etionina. Memorias $X$ Congreso Chileno de Química Clínica, Talca, Chile.

Mayo J, R Sainz, I Antoli, F Herrera, V Martin, C Rodriguez. 2002. Melatonin regulation of antioxidant enzyme gene expression. Cell Mol Life Sci 59, 1706-1713.

Melchiorri D, R Reiter, A Attia, M Hara, A Burgos, G Nistico. 1995. Potent protective effect of melatonin on in vivo paraquat-induced oxidative damage in rats. Life Sci 56, 83-89.
Melchiorri D, R Reiter, E Sewerynek, M Hara, L Chen, G Nistico, 1996. Paraquat toxicity and oxidative damage: Reduction by melatonin. Biochem Pharmacol 51, 1095-1099.

Menéndez-Peláez A, R Reiter. 1993. Distribution of melatonin in mammalian tissues: the relative importance of nuclear versus cytosolic localization. J Pineal Res 15, 59-69.

Naji L, A Carrillo-Vico, J Guerrero, J Calvo. 2004. Expression of membrane and nuclear melatonin receptors in mouse peripheral organs. Life Sci 74, 2227-2236.

Ohkawa H, N Ohishi, K Yagi. 1979. Assay for lipid peroxides in animal tissues by thiobarbituric acid reaction. Anal Biochem 95, 351-358.

Ohta Y, M Kongo-Nishimura, T Matsura, K Yamada, A Kitagawa, T Kishikawa. 2004. Melatonin prevents disruption of hepatic reactive oxygen species metabolism in rats treated with carbon tetrachloride. $J$ Pineal Res 36, 10-17.

Reiter R, D Tan, B Poeggeler, A Menendez-Pelaez, L Chen, S Saarela. 1994. Melatonin as a free radical scavenger: implications for aging and age related diseases. Ann NY Acad Sci 719, 1-12.

Reiter R. 1995. Functional pleiotropy of the neurohormone melatonin: antioxidant protection and neuroendocrine regulation. Front Neuroendocrinol 16, 383-415.

Reiter R. 1996. Functional aspects of the pineal hormone melatonin in combating cell and tissue damage induced by free radicals. Eur $J$ Endocrinol 134, 412-420.

Ruiz M, A López-Ortega. 2000. Concentración de MDA en hígado graso inducido por una dosis alta de oxitetraciclina en ratones preñadas. Acta Cient Venez 51 (Supl. 2), 101.

Suzuki Y, H Forman, A Sevanian. 1997. Oxidants as stimulators of signal transduction. Free Radic Biol Med 22, 269-285.

Tan D, B Poeggeler, R Reiter, L Chen, S Chen, L Manchester, L Barlow. 1993. The pineal hormone melatonin inhibits DNA adduct formation induced by chemical carcinogen safrole in vivo. Cancer Lett 70, 65-71.

Tan D, R Reiter, L Chen, B Poeggeler, L Manchester, L Barlow. 1994. Both physiological and pharmacological levels of melatonin reduce DNA adduct formation induced by the carcinogen safrole. Carcinogenesis 15, 215-218.

Trinder P. 1984. Enzymatics methods, Ann Clin Biochem 6, 24-27.

Turjanski A, R Rosenstein, D Estrin. 1998. Reactions of melatonin and related indoles with free radicals: a computational study. $\mathrm{J}$ Med Chem 41, 3684-3689.

Wallin B, B Rosengren, H Shertzer, G Camejo. 1993. Lipoprotein oxidation and measurement of thiobarbituric acid reacting substances formation in a single microtiter plate: Its use for evaluation of antioxidants. Anal Biochem 208, 10-15.

Wiesenberg I, M Missbach, C Calberg. 1998. The potential role of the transcription factor RZR/ROR as a mediator of nuclear melatonin signaling. Restor Neurol Neurosci 12, 143-150.

Winiarska K, T Fraczyk, D Malinska, J Drozak, J Bryla. 2006. Melatonin attenuates diabetes-induced oxidative stress in rabbits. $J$ Pineal Res 40, 168-76.

Yokota F, Y Igarashi, R Suzue. 1982. Effects of ethionine feeding on fatty liver and plasma lipoprotein in rats. J Nutr 112, 405-409. 